\title{
Expression of aldo-keto reductase family 1 member C1 (AKR1C1) gene in porcine ovary and uterine endometrium during the estrous cycle and pregnancy
}

Kyeong-Seok Seo ${ }^{1 \dagger}$, Purevjargal Naidansuren ${ }^{1 \dagger}$, Sang-Hwan Kim, Seong-Jo Yun ${ }^{1}$, Jong-Ju Park', Bo-Woong Sim', Cha-Won Park', Tseeleema Nanjidsuren', Myung-Hwa Kang², Heewon Seo ${ }^{3}$, Hakhyun Ka ${ }^{3}$, Nam-Hyung Kim4, Sue-Yun Hwang ${ }^{1}$, Jong-Taek Yoon ${ }^{1}$, Keitaro Yamanouchi ${ }^{5}$ and Kwan-Sik Min ${ }^{1 *}$

\begin{abstract}
Background: The aldo-keto reductase family 1 member C1 (AKR1C1) belongs to a superfamily of NADPHdependent reductases that convert a wide range of substrates, including carbohydrates, steroid hormones, and endogenous prostaglandins. The 20alpha-hydroxysteroid dehydrogenase (20alpha-HSD) is a member of AKR family. The aims of this study were to determine its expression in the ovary and uterus endometrium during the estrous cycle and pregnancy.

Methods: Rapid amplification of CDNA ends (RACE) experiments were performed to obtain the $5^{\prime}$ and $3^{\prime}$ ends of the porcine 20alpha-HSD cDNA. Reverse-transcriptase-PCR (RT-PCR), real-time PCR, northern blot analysis, and western blot analysis were performed to examine the expression of porcine 20alpha-HSD. Immunohistochemical analysis was also performed to determine the localization in the ovary.

Results: The porcine 20alpha-HSD cDNA is 957 bp in length and encodes a protein of 319 amino acids. The cloned CDNA was virtually the same as the porcine AKR1C1 gene (337 amino acids) reported recently, and only differed in the $\mathrm{C}$-terminal region (the $A K R 1 C 1$ gene has a longer $\mathrm{C}$-terminal region than our sequence). The 20alpha-HSD gene (from now on referred to as AKR1C1) cloned in this paper encodes a deletion of 4 amino acids, compared with the C-terminal region of AKR1C1 genes from other animals. Porcine AKR1C1 mRNA was expressed on day 5, 10, 12, 15 of the cycle and 0-60 of pregnancy in the ovary. The mRNA was also specifically detected in the uterine endometrium on day 30 of pregnancy. Western blot analysis indicated that the pattern of AKR1C1 protein in the ovary during the estrous cycle and uterus during early pregnancy was similar to that of AKR1C1 mRNA expression. The recombinant protein produced in $\mathrm{CHO}$ cells was detected at approximately $37 \mathrm{kDa}$. Immunohistochemical analysis also revealed that pig AKR1C1 protein was localized in the large luteal cells in the early stages of the estrous cycle and before parturition.
\end{abstract}

Conclusions: Our study demonstrated that AKR1C1 mRNA and protein are coordinately expressed in the luteal cell of ovary throughout the estrous cycle and in the uterus on day 30 of pregnancy. Thus, the porcine AKR1C1 gene might control important mechanisms during the estrous cycle.

\footnotetext{
* Correspondence: ksmin@hknu.ac.kr

† Contributed equally

'Animal Biotechnology, Graduate School of Bio \& Information Technology, Institute of Genetic Engineering, Hankyong National University, Ansung 456749 , Korea

Full list of author information is available at the end of the article
} 


\section{Background}

The aldo-keto reductase (AKR) superfamily are monomeric oxidoreductases that catalyze the NADP(H)-dependent reduction of a wide variety of substrates, including steroids, prostaglandins, bile acids, carbohydrates, and xenobiotics [1]. A group of AKRs known as hydroxysteroid dehydrogenases (HSDs) play a pivotal role in the modulation and regulation of steroid hormones [2], such as androgens, estrogens, and progestins, and are thus considered important targets for drug design [3]. AKR1C1, a member of the AKR1C subfamily (that shows both $20 \alpha-$ and $3 \alpha-H S D$ activities), plays a major role in progesterone metabolism and maintenance of pregnancy through the formation of progestin. AKR1C1 also has high 20 $\alpha$-HSD activity [4]. Animal AKRs are involved in a wide range of cellular processes that include the biosynthesis of steroid hormones in classical steroidogenic tissues [1].

The products of AKR activity have been implicated in prostate disease, breast cancer, obesity, polycystic ovary disease, and delay in onset of puberty in humans $[5,6]$. $A K R 1 C$ genotypes are associated with nipple number as well as having possible effects on age at puberty and ovulation rate in pigs [7]. In swine, the rate of pubertal development and successful pregnancy in gilts affects the efficient

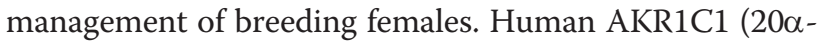
HSD) has been functionally expressed in the fission yeast, and that this has enabled the resulting yeast strain to efficiently catalyze the reduction of progesterone to $20 \alpha$-dihydroprogesterone. Thus, the process of AKR-dependent whole-cell biotransformation has been established, to be used for the production of human AKR metabolites on a large scale [8].

A tissue distribution study has demonstrated that $20 \alpha-$ HSD is expressed in the placenta, but not in the adrenal gland, liver, or spleen during pregnancy. The $20 \alpha-H S D$ mRNA is expressed in the uterus and fetal skin during pregnancy and has been suggested to play a role in maintaining pregnancy in goats [9]. The $20 \alpha-$ HSD enzyme plays a critical role in the regulation of luteal function and is also localized in the placenta of rats [10], goats [9], and humans [4]. Histochemical data have illustrated strong $20 \alpha$-HSD activities in several large luteal cells but not in granulosa cells $[11,12]$. In ruminant animals, goat $20 \alpha-H S D$ mRNA is mainly localized in the endometrial epithelium on the caruncle side of the placenta [13]. In pigs, all $A K R 1 C$ genes are expressed in adult tissues (spleen, lung, ovary, adrenal, gland, kidney, and endometrium). Pig $A K R 1 C 4$ is expressed in all tissues, and $A K R 1 C 2$ is the only other $A K R 1 C$ gene expressed in the brain [7]. The $A K R 1 C 1$ gene is widely expressed in adult tissues, but is not expressed in the pancreas, pituitary gland, small intestine, or brain. However, the regulation of the temporal expression pattern of $A K R 1 C 1$ in reproductive tissues (ovary and uterus) during the estrous cycle and pregnancy are not completely understood.

To gain further insights into the expression and localization of AKR1C1 in the porcine ovary and uterine endometrium during the estrous cycle and pregnancy, we analyzed the mRNA and protein using RT-PCR, real-time PCR, northern blot analysis, western blot analysis, and immunohistochemistry.

\section{Methods \\ Materials}

The cloning vector $\mathrm{pCR} 2.1$, expression vectors pcDNA3 and pcDNA4/HisMax, GeneRacer kit, and Super Script ${ }^{\mathrm{TM}}$ First-Strand synthesis system were purchased from Invitrogen Life Technologies (Carlsbad, CA). The GLASSMILK gel extraction kit was purchased from Q-BIO gene (Cambridge, UK). Restriction enzymes and DNA ligation kits were bought from Takara (Tokyo, Japan). The OneStep SYBR RT-PCR kit was purchased from Toyobo (Osaka, Japan). Pro-PREPTM protein extraction solution was purchased from Intron Biotechnology (Seoul, Korea). The Digoxigenin (DIG) DNA labeling kit and Lumi-Light western blot kit were bought from Roche (Roche, Germany). Horse serum, goat serum, the avidin-biotinhorseradish peroxidase $(\mathrm{ABC})$ detection kit, 3,3'-diaminobenzidine (DAB), hematoxylin, and methyl green were purchased from Vector Laboratories (Burlinggame, CA). Anti-rabbit immunoglobulins and anti-rabbit Alexa 488 secondary antibody were bought from Dako Cytomation. E-scherichia. coli competent cells (ECOS) were obtained from Yeastern Biotech Co. Ltd. (Seoul, Korea). CHO-K1 cells were obtained from the Japanese Cancer Research Resources Bank (Tokyo, Japan). Ham's F-12, Opti-Minimal Essential Medium (MEM) I, serum-free CHO-S-SFM II, and Lipofectamine ${ }^{\mathrm{TM}} 2000$ reagents were bought from Gibco BRL (MD, USA). Fetal bovine serum was from Hyclone Laboratories (UT, USA). The oligonucleotides were synthesized by Genotech (Daejon, Korea), and all other chemicals were obtained from local suppliers.

\section{Tissues}

Ovary tissues were obtained by laparotomy of pigs under general anesthesia on days $0,2,5,10$, and 15 of the estrous cycle. Ovaries were also collected from pigs on days 0,30 , and 60 of pregnancy, and before parturition. Uteri were obtained from pigs on days 12 and 15 of the estrous cycle, and at days 12, 15, and 30 of pregnancy. Tissues were completely washed 2 times in icecold phosphate-buffered saline ( $\mathrm{pH}$ 7.2) and dissected into small fragments. Tissues were snap-frozen in liquid nitrogen and stored at $-80^{\circ} \mathrm{C}$. The experiments were conducted according to the Guidelines for the Care and Use of Animals, Hankyong National University. 


\section{Preparation of porcine AKR1C1 fragments}

PCR primers were designed according to the previously reported homologous part of the 20 $\alpha-H S D$ cDNA sequence $[4,9,13]$. The specific primers (sense: 5'-GTG AAG AGA GAA GAC ATA TTC-3' and antisense: 5'CCA CGT TGT ATC TGG TAG CGA AGG-3') were synthesized from the nucleotide sequence of the cloned $20 \alpha-H S D$ gene. Total RNA was extracted using the Trizol reagent. cDNA synthesis was performed using the SuperScript ${ }^{\mathrm{TM}}$ First-Strand Synthesis System according to the manufacturer's instructions. PCR was performed with 2.5 units of pfu polymerase in Quick Thermo-II using the following parameters: 30 cycles of denaturation $\left(91^{\circ} \mathrm{C}\right.$ for $1 \mathrm{~min})$, annealing $\left(37^{\circ} \mathrm{C}\right.$ for $\left.1 \mathrm{~min}\right)$, and extension $\left(72^{\circ} \mathrm{C}\right.$ for $2 \mathrm{~min}$ ). The PCR products were analyzed by electrophoresis in Tris-acetate containing EDTA (TAE). The PCR fragments (572 bp) were ligated into the pCR2.1 vector and sequence data were analyzed using computer software (DNASIS).

\section{3'- and 5'-Rapid Amplification of cDNA Ends system}

GeneRacer 3'-primer (5'-GCT GTC AAC GAT ACG CTA CGT AAC G-3'), and GeneRacer 3'-nested primer (5'CGC TAC GTA ACG GCA TGA CAG TG-3') for 3'rapid amplification of cDNA ends (RACE) were designed according to the nucleotide sequence of the resulting PCR product. The gene specific primer (GSP) GeneRacer 5'-primer (5'-CGA CTG GAG CAC GAG GAC ACT GA-3'), and the GeneRacer 5'-nested primer (5'-GGA CAC TGA CAT GGA CTG AAG GAG TA-3') for 5'-RACE were designed according to the nucleotide sequence of the resulting PCR product. The 3'- and 5'-RACE experiments were performed using the GeneRacer kit (Invitrogen, USA) and conducted according to the manufacturer's instructions. To confirm the sequence accuracy for the stop codon in the 3'-terminal region, we conducted the PCR with specific primers (sense: 5'-GTG AAG AGA GAA GAC ATA TTC-3' and antisense: 5'-GAA GTG TCT GCA CTT CTG AAA GCT-3').

\section{RT-PCR and real-time PCR of porcine AKR1C1 mRNA expression}

RT-PCR was performed using the AccuPower RT-PCR kit (RT/PCR PreMix). Total RNA $(1.0 \mu \mathrm{g})$ extracted from the pig ovary on days $0,5,10$, and 15 of the estrous cycle was mixed with the reverse primer (5'-GCC ATT GCC AAA AAG CAC AAG-3'), incubated at $70^{\circ} \mathrm{C}$ for $5 \mathrm{~min}$, and placed on ice. The forward primer (5'-GGA AAG CGG ATA GTC AGG GTG ATC-3') was then added, and the reaction volume was brought to $20 \mu \mathrm{L}$ by adding diethylpyrocarbonate-distilled water (DEPC-DW). The cDNA synthesis reaction was performed using the following parameters: $42^{\circ} \mathrm{C}$ for $60 \mathrm{~min}$ and $94^{\circ} \mathrm{C}$ for $5 \mathrm{~min}$. PCR was carried out according to the following parameters: $94^{\circ} \mathrm{C}$ for
$1 \mathrm{~min}$, followed by 30 cycles $\left(94^{\circ} \mathrm{C}\right.$ for $1 \mathrm{~min}, 56^{\circ} \mathrm{C}$ for $1.5 \mathrm{~min}$, and $72^{\circ} \mathrm{C}$ for $1 \mathrm{~min}$ ), followed by a final extension at $72^{\circ} \mathrm{C}$ for $8 \mathrm{~min}$. Primers for glyceraldehyde-3-phosphate dehydrogenase (GAPDH) were used for the normalization of porcine $20 \alpha-H S D$ expression and the primer sequences of the forward and reverse primers were 5'-ACC ACA GTC CAT GCC ATC AC-3' and 5'-TCC ACC ACC CTG TTG CTG TA-3', respectively. The expected length of the PCR fragment was $452 \mathrm{bp}$. The PCR conditions were 26cycles for $10 \mathrm{~s}$ at $98^{\circ} \mathrm{C}, 20 \mathrm{~s}$ at $55^{\circ} \mathrm{C}$, and $20 \mathrm{~s}$ at $72^{\circ} \mathrm{C}$. Gel electrophoresis was used to analyze $10 \mu \mathrm{L}$ of the PCR products. Real-time PCR was carried out using a One-Step SYBR RT-PCR kit. The real-time PCR amplification mixture consisted of the following reagents: a total of $5 \mu \mathrm{g}$ of RNA, $1 \times$ of $2 \times$ One-Step SYBR RT-PCR buffer, 5 pmol of each primer, $2.5 \mathrm{U}$ of Takara Ex Taq HS (Takara, Japan), $50 \mathrm{U}$ of Moloney murine leukemia virus (M-MLV) RTase (RNase $\mathrm{H}$ free), and $20 \mathrm{U}$ of RNase inhibitor. This mixture was added to PCR tubes, and the reaction volume was brought to $25 \mu \mathrm{L}$ by adding RNase-free $\mathrm{dH}_{2} \mathrm{O}$. The thermocycler profile was $10 \mathrm{~min}$ at $95^{\circ} \mathrm{C} ; 30$ cycles of $10 \mathrm{~s}$ at $95^{\circ} \mathrm{C}, 15 \mathrm{~s}$ at $56^{\circ} \mathrm{C}$, and $20 \mathrm{~s}$ at $72^{\circ} \mathrm{C}$; followed by $45 \mathrm{~s}$ at $72^{\circ} \mathrm{C}$.

\section{Northern blotting analysis}

For northern blot analysis, RNA electrophoresis was performed on an agarose gel containing 10' MOPS and 37\% formaldehyde. The total RNA concentration from pig ovary and uterus was adjusted to $10 \mu \mathrm{g} / \mu \mathrm{L}$. Following electrophoresis, RNA was transferred overnight to a membrane with 20' SSC. The probe was prepared by purifying the sample after PCR amplification. Probe labeling was performed with the DIG DNA Labeling Kit. The membrane was prehybridized for $1 \mathrm{~h}$ at $68^{\circ} \mathrm{C}$ and hybridized at $68^{\circ} \mathrm{C}$ overnight with DIG-labeled pig AKR1C1 cDNA with gentle rocking. The membrane was subsequently washed 2 times with buffer (2' SSC/0.1\% SDS) at $68^{\circ} \mathrm{C}$ for $5 \mathrm{~min}$ with gentle rocking, and 2 times with $0.5^{\prime}$ $\mathrm{SSC} / 0.1 \% \mathrm{SDS}$ at $68^{\circ} \mathrm{C}$ for $15 \mathrm{~min}$ with gentle rocking. The anti-DIG antibody $(5 \mu \mathrm{L})$ was mixed with blocking reagent, added to the membrane, and incubated at room temperature (RT) for $1 \mathrm{~h}$. The membrane was washed 2 times with washing buffer at RT for $15 \mathrm{~min}$, and equilibrated with detection buffer at RT for $5 \mathrm{~min}$. The band was detected by the addition of CDP-Star reagent.

\section{Western blot analysis}

Total protein was extracted using the PRO-PREPTM protein extraction solution. About 10-20 mg of ovarian and uterus tissues was used. The samples were then homogenized in $600 \mu \mathrm{L}$ of PRO-PREPTM solution, and cell lysis was induced by incubation on ice for $30 \mathrm{~min}$. The tube was centrifuged at $13,000 \mathrm{rpm}$ at $4^{\circ} \mathrm{C}$ for $5 \mathrm{~min}$, and the supernatant was transferred to a fresh $1.5-\mathrm{mL}$ tube. 
Protein concentration was measured using the Bradford protein assay [14]. Samples were subjected to SDS-PAGE and transferred to a polyvinylidene fluoride (PVDF) membrane $(0.2 \mu \mathrm{m})$ through a semidry electroblotter apparatus. The membrane was blocked with $1 \%$ blocking reagent for $1 \mathrm{~h}$ and incubated with a 1:1,500 dilution of bovine-specific polyclonal $20 \alpha-H S D$ antibody for $1 \mathrm{~h}$. The membrane was washed to remove unbound antibody and incubated with a 1:2,000 dilution of a secondary antibody linked to anti-rabbit IgG-peroxidase (POD) for $30 \mathrm{~min}$. Next, the membrane was incubated for 5 min with Lumi-Light substrate solution $(2 \mathrm{~mL})$, covered with plastic wrap, and exposed to X-ray film for 1-10 min.

\section{Construction of expression transfer vector and transient transfection of $\mathrm{CHO}$ cell lines}

The full-length pig $A K R 1 C 1$ cDNA was PCR-amplified with specific primers containing a 5'-end XhoI restriction site in the $A K R 1 C 1 \mathrm{cDNA}$ sequence, and a 3'-end $X b a \mathrm{I}$ site in the sequence cloned in this study. The PCR fragments were ligated into the PCR2.1 vector and sequenced. The fragments digested with $\mathrm{XhoI}$ and $\mathrm{Xba \textrm {I }}$ restriction enzymes were ligated into eukaryotic expression vectors (pcDNA3 and pcDNA4/His Max) that had been digested with $X h o \mathrm{I}$ and $\mathrm{XbaI}$ (designated as pcDNA3-pAKR1C1 and pcDNA4/His Max-pAKR1C1). Each vector was completely sequenced to confirm the presence of the Kozak site and to rule out the possibility of PCR errors. CHO-KI cell lines were cultured in growth medium (Ham's F12 medium containing penicillin $[50 \mathrm{U} / \mathrm{mL}]$, streptomycin $[50 \mathrm{mg} / \mathrm{mL}]$, glutamine $[2$ $\mathrm{mM}]$, and $10 \%$ fetal calf serum). The cells were incubated at $37^{\circ} \mathrm{C}$ in $5 \% \mathrm{CO}_{2}$. Cultured $\mathrm{CHO}-\mathrm{K} 1$ cells were transfected with the expression vectors by using the liposome transfection method described previously [15]. Briefly, DNA $(0.8 \mu \mathrm{g})$ was diluted in $50 \mu \mathrm{L}$ of OptiMEM I reduced medium without serum and mixed gently. Lipofectamine $2000(2 \mu \mathrm{L})$ was added gently to a separate $50-\mu \mathrm{L}$ aliquot of Opti-MEM I medium. Each tube was incubated separately for $5 \mathrm{~min}$ at RT, after which the diluted DNA and the diluted Lipofectamine 2000 were combined into a single tube. The 2 samples were mixed gently and incubated for $20 \mathrm{~min}$. A $100-\mu \mathrm{L}$ aliquot of DNA-Lipofectamine 2000 complex was added to each well, and the samples were incubated for 4-6 h, and then, $250 \mu \mathrm{L}$ of $20 \%$ FBS was added to each well. The cells were incubated at $37^{\circ} \mathrm{C}$ in a $\mathrm{CO}_{2}$ incubator for $24 \mathrm{~h}$. The following day, transfected cells were washed 2 times, placed in $500 \mu \mathrm{L}$ of serum-free medium, and incubated at $37^{\circ} \mathrm{C}$ for $48 \mathrm{~h}$. Next, the culture medium was removed and the cells were collected into a tube. Subsequently, the cells were centrifuged at 15,000 rpm for $10 \mathrm{~min}$, and the cell debris was recovered.
Immunoblot analysis of recombinant pig AKR1C1 protein Recombinant protein was extracted using PRO-PREP protein extraction solution. Recombinant AKR1C1 proteins were subjected to SDS-PAGE and transferred to a PVDF membrane through a semidry electroblotter apparatus. The western blot analysis method described above was followed.

\section{Immunohistochemistry}

Immunohistochemical staining was performed using the Vectastain ABC kit. Ovary samples taken on days 2, 5, 10, and 15 of the estrous cycle and before parturition were fixed in 10\% neutral buffered formalin at RT for $24 \mathrm{~h}$ and washed with PBS. Next, the fixed samples were dehydrated in graded ethanol (EtOH) (3 min each in 50\%, 2'; 70\%, 1'; 95\%, 1(; 100\%, 1() and dealcoholized with xylene for $2 \mathrm{~h}$ and embedded in paraffin. Paraffin-embedded tissues were sectioned at $8 \mu \mathrm{m}$ and mounted onto poly l-lysine-coated slides and dried at RT. The slides were deparaffinized and rehydrated (3 min each in xylene, 2(; 100\% EtOH, 2(; 95\% EtOH, 1(; 70\% EtOH, 1(; 50\% EtOH 1() and kept in the cold tap water. The slides were boiled in $10 \mathrm{mM}$ sodium citrate for $10 \mathrm{~min}$, left on ice for $20 \mathrm{~min}$, and then washed in 3\% hydrogen peroxide for $10 \mathrm{~min}$ and blocked for $1 \mathrm{~h}$ at RT. The slides were first incubated with the primary antibody for overnight for overnight at $4 \mathrm{C}$, followed by the anti-rabbit secondary antibody for $2 \mathrm{~h}$ at RT. Finally, the slides were immunostained using the $\mathrm{ABC}$ detection kit, stained with $\mathrm{DAB}$, and observed under a Nikon Eclipse TE-2000-E confocal microscope.

\section{Data and statistical analysis}

One - Way ANOVA Newman-Keuls Multiple Comparison tests were used to compare results between control and samples, using GraphPad Prism 5 (GraphPad Software). Asterisks indicate significant differences from the control group. ("p $<0.05$, "**" $\mathrm{p}<0.01$, ***p $\mathrm{p}<0.001$ ).

\section{Results}

\section{Determination of AKR1C1 C-terminal region nucleotide} sequence

The complete cDNA sequence $(957 \mathrm{bp})$ for porcine $A K R 1 C 1$ was obtained by assembly of the sequences from the PCR and RACE fragments. A BLAST search of the porcine reference genome sequence in the NCBI database by using the porcine $A K R 1 C 1 \mathrm{cDNA}$ did not help identify the corresponding gene sequence. The porcine $A K R 1 C 1$ cDNA encodes a protein of 319 amino acids (GenBank: JN62505). Based on the results of 3'-RACE, we detected a stop codon in a different site from that of porcine AKR1C1 reported previously [7]. We sequenced 20 clones from the 3'-RACE experiment to confirm the sequence accuracy. This result was different from the 337 amino 
acids sequence of pig AKR1C1 that was previously reported, and there was a deletion of 4 amino acids compared with other animal $20 \alpha-H S D$ sequences reported to date (Figure 1).

\section{Expression of AKR1C1 mRNA by RT-PCR and real-time PCR}

By using the specific primers for porcine $A K R 1 C 1$ and amplification by RT-PCR and real-time PCR, porcine AKR1C1 mRNA was expressed on day 5, 10, 12, 15 of the cycle and 0-60 of pregnancy in the ovary (Figure 2A, B). The RT-PCR and real-time PCR results were almost the same. The AKR1C1 mRNA was detected in all ovarian tissues during the estrous cycle. However, the expression of $A K R 1 C 1$ mRNA was particularly strong in the ovary on day 0 of the estrous cycle. mRNA expression in the ovary gradually decreased and was very low in the ovary on day 15 of the estrous cycle.

\section{Northern blot analysis}

For northern blot analysis, total RNA was extracted from porcine ovarian tissues on days 5,10 , and 15 of the estrous cycle, and on days 0,30 , and 60 of pregnancy and before parturition. Northern blot analysis revealed a $1.2-\mathrm{kb}$ mRNA in the ovary on day 5 of the estrous cycle and before parturition (Figure 3A). This pattern was very similar to the RT-PCR and real-time PCR results. This mRNA was more intensively expressed in the pre-parturition ovary than in the ovary at any other period during pregnancy (Figure 3B). Next, we analyzed the expression difference in the ovary on day 12 of the estrous cycle and pregnancy. An intense pig AKR1C1 mRNA band was detected with a size of approximately $1.2 \mathrm{~kb}$ in the ovary on day 12 of pregnancy (Figure 4A). Moreover, we also specifically detected $A K R 1 C 1 \mathrm{mRNA}$ in the uterus on day 30 of pregnancy, but it was not detected in the uterus on days 12 and 15 of the estrous cycle and on days 12 and 15 of pregnancy (Figure 4B).

\section{Western blot analysis of pig ovary tissues}

Pig AKR1C1 protein was detected at approximately $37 \mathrm{kDa}$ by western blot analysis, using a specific antibovine $20 \alpha-H S D$ antibody developed in our laboratory. AKR1C1 protein was detected in all ovaries during the estrous cycle. The highest expression of the protein was detected on day 0 of the estrous cycle. Thereafter, its expression gradually decreased. The level of the protein was remarkably decreased in the ovary on day 15 of the estrous cycle (Figure 5A). Comparison of the level of the AKR1C1 protein with that of the mRNA in ovaries during the estrous cycle showed a similar pattern. Interestingly, 2 protein bands were detected at approximately 37 and $39 \mathrm{kDa}$ in the ovarian tissues during estrous cycle (Figure 5A). Next, we analyzed the expression in the uterus on days 12 and 30 of pregnancy. An intense protein band was detected with a size of approximately $37 \mathrm{kDa}$ in the uterus on day 30 of pregnancy (Figure $5 B)$. But, it was not detected in the uterus on day 12 of pregnancy.

\section{Expression of recombinant AKR1C1 in the CHO-K1 cell line} Two expressing vectors (pcDNA3 + pig AKR1C1 and pcDNA4/HisMax + pig AKR1C1) were transiently transfected into CHO-K1 cells. The cell lysates were collected and subjected to SDS-PAGE. Bovine 20 $\alpha$-HSDspecific antibody was used to detect the recombinant protein. The recombinant protein produced by the pcDNA4/HisMax + pig AKR1C1 expression vector has a tagging protein of $4 \mathrm{kDa}$. Thus, the protein produced in this vector was detected at about $41 \mathrm{kDa}$. The recombinant protein of $37 \mathrm{kDa}$ was produced by the pcDNA3 vector (Figure 6).

\section{Immunohistochemical localization of AKR1C1 protein in} the ovary during the estrous cycle and before parturition To determine the cell types responsible for AKR1C1 protein expression in the ovary, we performed

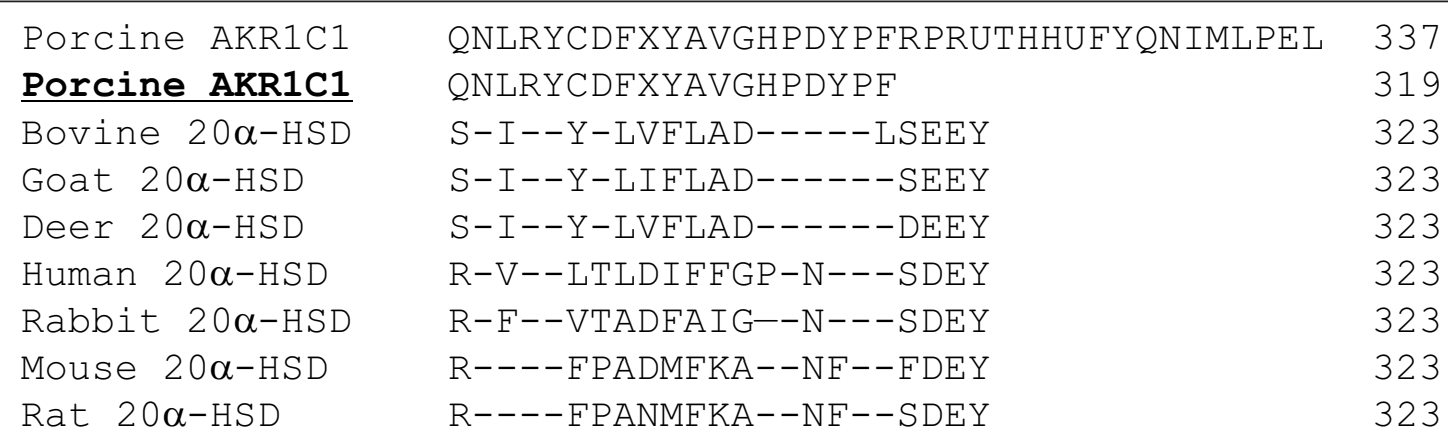

Figure 1 Amino acid alignment of pig AKR1C1 and other animal 20 $\alpha$-HSD proteins. A C-terminal amino acid region of pig AKR1C1 sequence was compared that of bovine, goat, deer, human, rabbit, mouse, and rat 20 $\alpha$-HSD. Dashed lines denote the amino acids identities. The numbers denote the amino acids before the stop codon. Porcine AKR1C1 denotes the results reported previously [7]. Bold and underlined AKR1C1 was shown sequence cloned in this paper. 


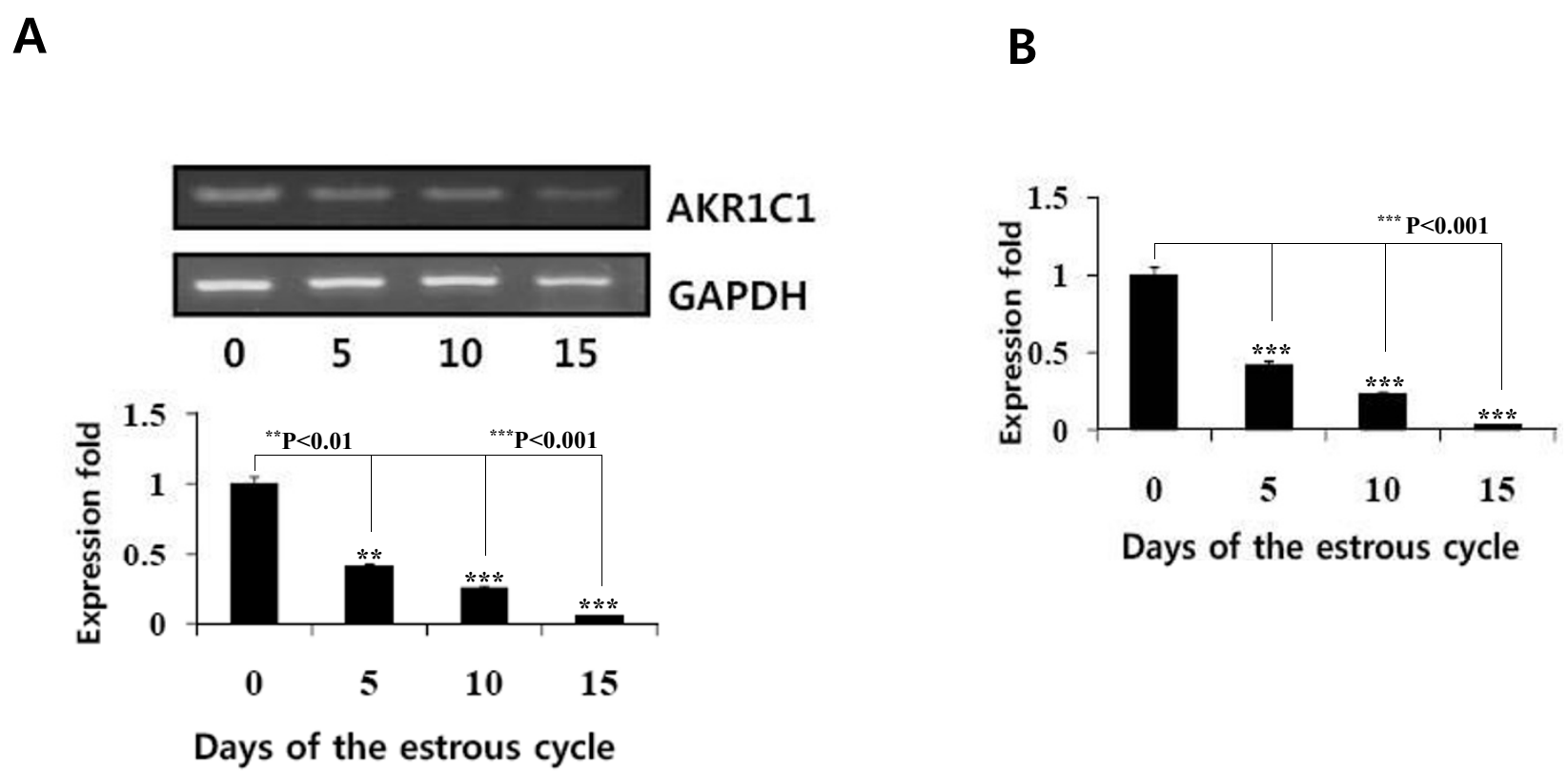

Figure 2 AKR1C1 mRNA expression in the ovary during the estrous cycle. A. AKR1C1 mRNA was detected by RT-PCR. B. Real-time PCR results. Ovarian tissues were obtained by laparotomy under general anesthesia on days $0,5,10$, and 15 of the estrous cycle. Total RNA was extracted and then subjected to RT-PCR and real-time PCR. The amplified products of the AKR1C1 and GAPDH genes were separated on agarose gel and stained with ethidium bromide. Representative results are shown; graphs show the average \pm SEM of 3 independent experiments.

immunohistochemical analysis in the ovary on days 2,5 , 10 , and 15 of the estrous cycle and before parturition. As shown in Figure 7, the AKR1C1 protein was localized in large luteal cells. It was intensely expressed in the luteal cells on days 2 and 5 of the early estrous cycle (Figure 7B, C). It was also strongly localized in the luteal cells of ovary at before parturition (Figure 7F). However, its signal was not detected in the small luteal cells.

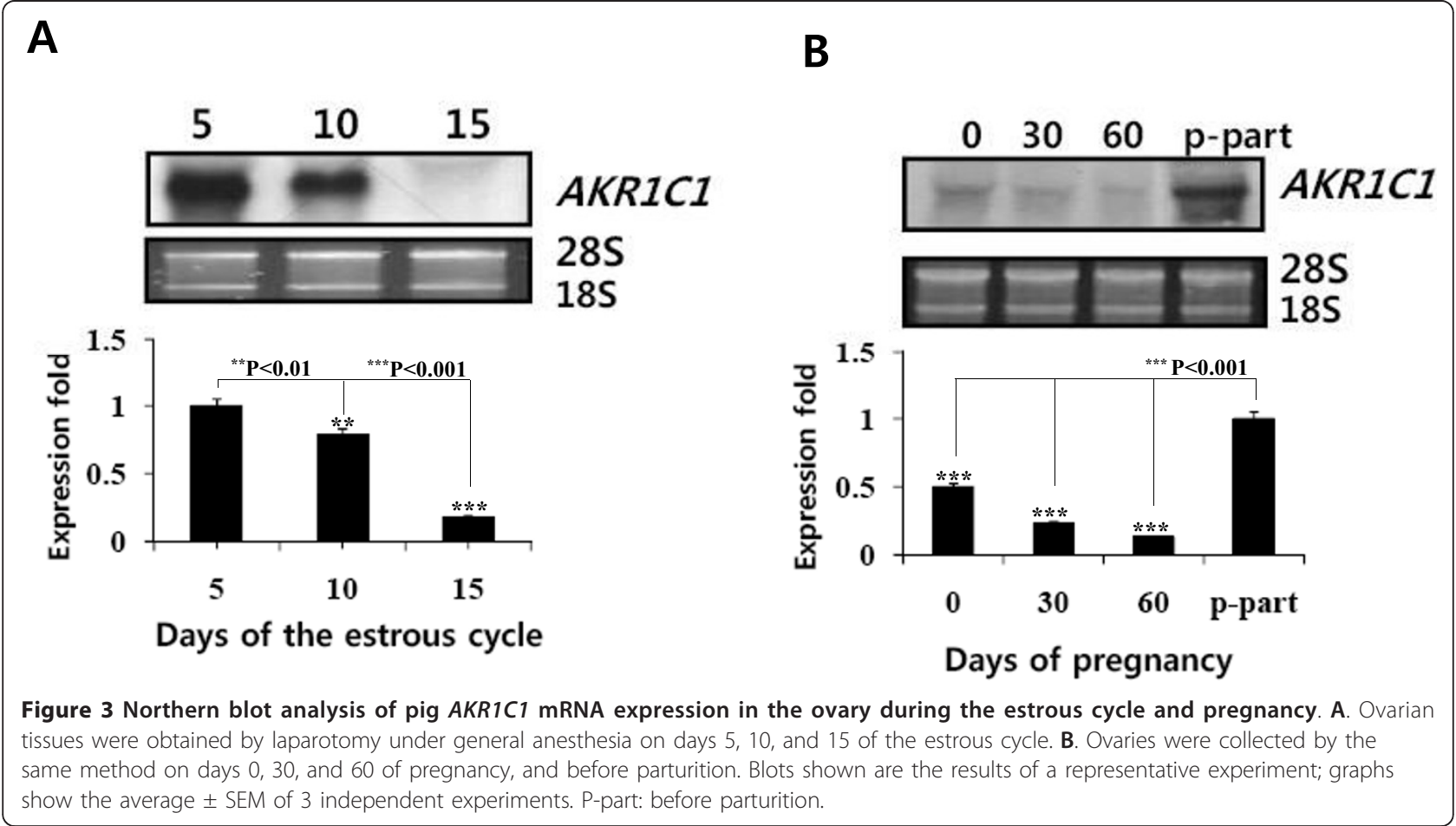


A

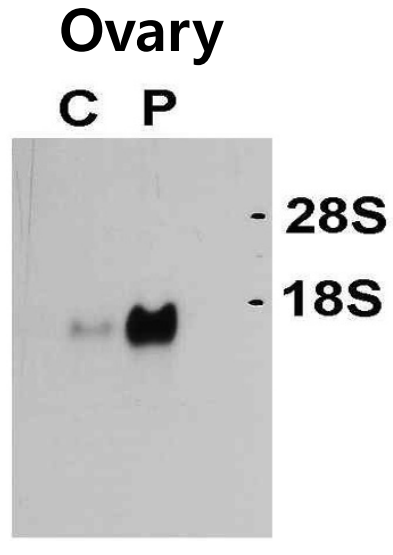

B

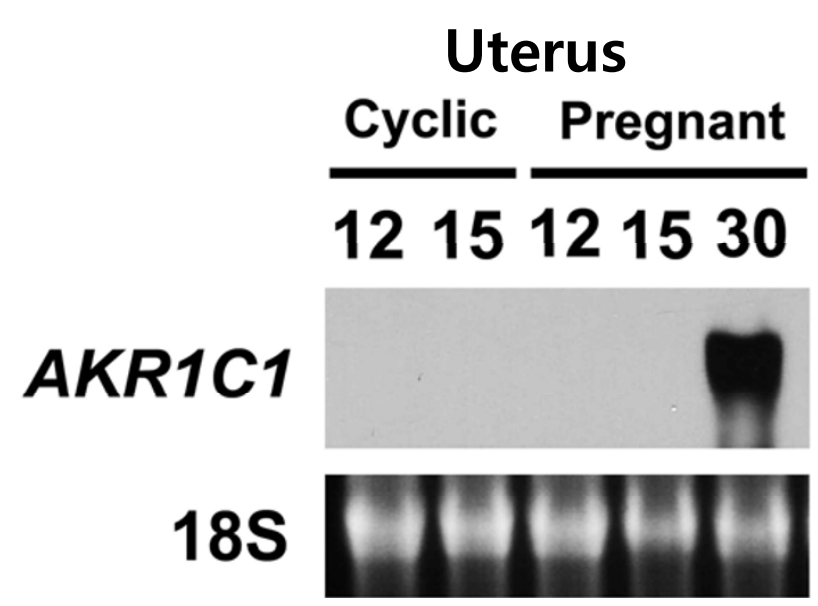

Figure 4 Northern blot analysis of pig AKR1C1 mRNA expression in the ovary and uterus during the estrous cycle and pregnancy. A. Total RNA was isolated from ovaries on day 12 of the estrous cycle and pregnancy. B. Uteri were collected on days 12 and 15 of the estrous cycle, and on days 12,15, and 30 of pregnancy. Blots shown are the results of a representative experiment; graphs show the average \pm SEM of 3 independent experiments. C: estrous cycle; P: pregnancy.

\section{Discussion}

In the present study, we determined the expression and localization of porcine AKR1C1 in the ovary and uterine endometrium through RT-PCR, real-time PCR, northern blotting, and immunohistochemistry during the estrous cycle and pregnancy. Analysis of the nucleotide sequence

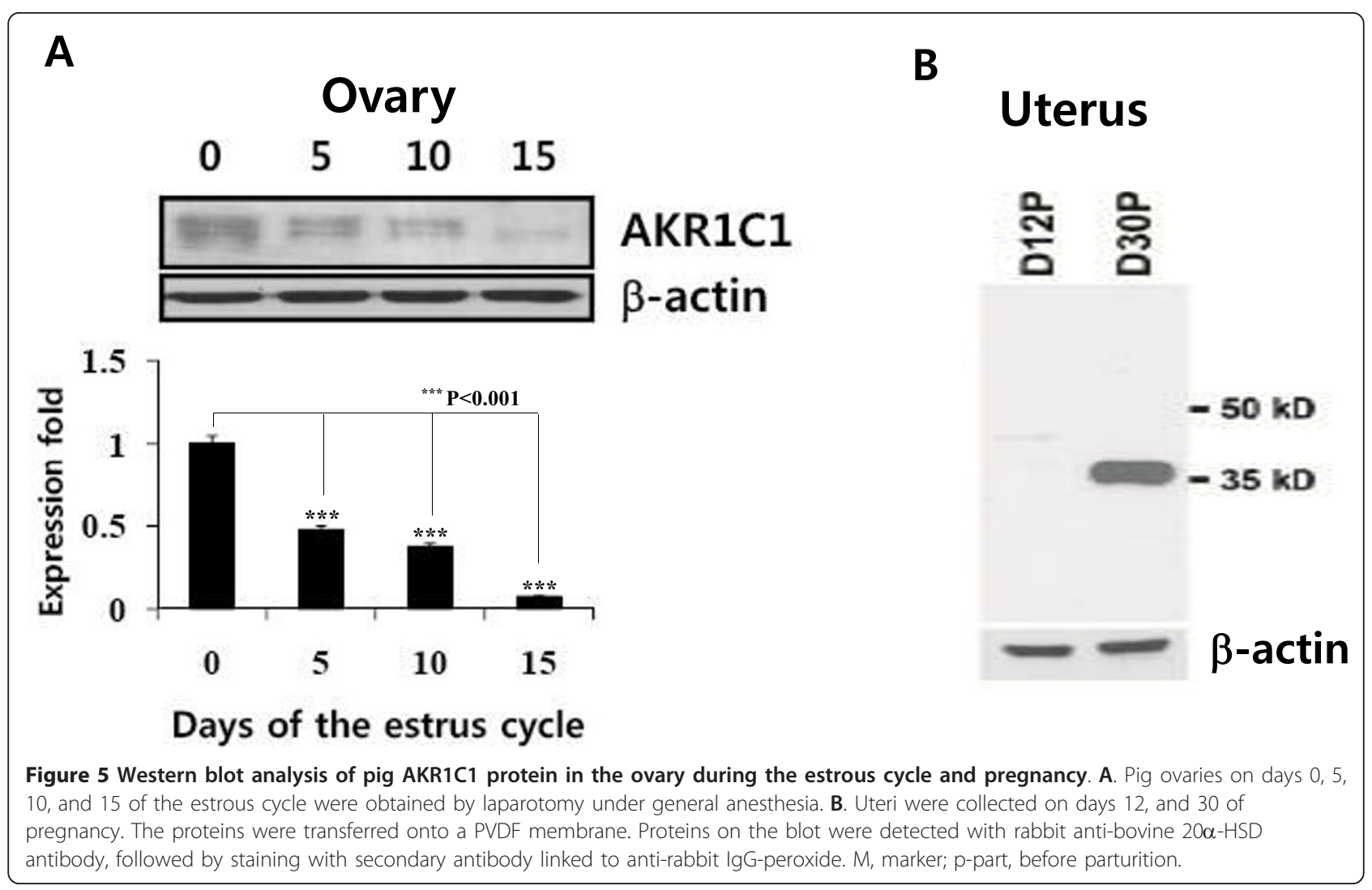




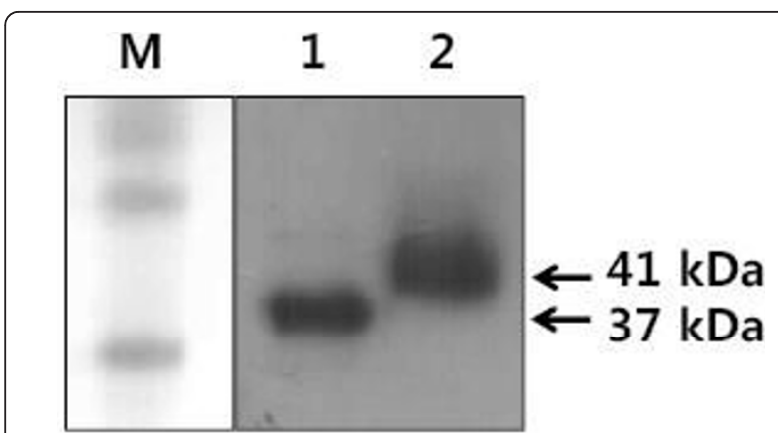

Figure 6 Immunoblot analysis of AKR1C1 recombinant protein in $\mathbf{C H O}-\mathbf{K} 1$ cells. The bands corresponding to the protein produced by pcDNA3 + pAKR1C1 and pcDNA4/HisMax + pAKR1C1 vectors were detected. After gel electrophoresis, the proteins were transferred to a nitrocellulose membrane. The protein on the blot was detected with rabbit anti-bovine 20 $\alpha-H S D$, followed by staining with anti-rabbit IgG-POD. Lane 1, pcDNA3 + pAKR1C1; lane 2, pcDNA4/HisMax + pAKR1C1.

by using the GenBank database revealed that porcine $A K R 1 C 1$ cDNA belongs to the AKR family. Both nucleotide and amino acid sequences of the porcine AKR1C1 cloned in this study showed high homology with those of bovine $(86 / 82 \%)$, goat $(80 / 78 \%)$, rat $(76 / 66)$, mouse (76/ $68 \%)$, and human (81/76\%) $20 \alpha-$ HSD. Based on the results of 3'-RACE, we detected a stop codon in a different site from that of porcine $A K R 1 C 1$ reported previously [7]. Several conserved sequence patterns were found in the porcine $A K R 1 C 1$ cloned in the present study. A catalytic tetrad, such as that consisting of Asp 50, Tyr 55, Lys 84, and His 117, is a common feature of the AKR family [1]. Other amino acids such as Gly 22, Gly 45, Asp 112, Pro 119, Gly 164, Asn 167, Pro 186, Gln 190, and Ser 271 are strictly conserved in the primary structure of all members of the AKR family [2]. Thus, these amino acids may play a role in conferring the appropriate tertiary structure necessary for the functional activity.

The present study confirmed that porcine AKR1C1 mRNA is expressed in ovarian tissues during the estrous cycle. This pattern was similar to the results of RT-PCR and real-time PCR results. As reported recently, porcine AKR1C1 gene is widely expressed in adult tissues as determined in a PCR study by Nonneman et al. [7]. However, these authors did not report on the expression level in the ovary during the estrous cycle and pregnancy. Although porcine $A K R 1 C 1$ mRNA is expressed in several tissues, our findings suggest that the expression level of $A K R 1 C 1$ mRNA in the ovary is different in the estrous cycle and in pregnancy. $A K R 1 C$ genotypes are associated with nipple number [16], as well as possibly having effects on age at puberty and ovulation rate in pigs $[7,17]$.

The expression of pig AKR1C1 mRNA was very different from that of bovine and goat $20 \alpha$-HSD during the estrous cycle. The bovine 20a-HSD level was remarkably higher in the corpus luteum during the late estrous cycle (unpublished results). On the other hand, goat 20 $\alpha$-HSD expression was found in the corpus luteum during the late estrous cycle and expressed in the placenta and intercaruncular region of the uterus during mid to late pregnancy, but not in the adrenal gland, liver, or spleen

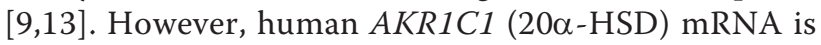
highly expressed in the liver, mammary gland, and brain, and is expressed at a low levels in the prostate, testis, adrenal gland, and uterus [4]. Albarracin et al. [18] indicated that the pattern of $20 \alpha$-HSD mRNA expression in the corpus luteum closely paralleled the ontogeny of $20 \alpha$-HSD enzyme activity. Pig AKR1C1 mRNA was also strongly expressed in the ovaries on day 12 of pregnancy and in the uterine endometrium on day 30 of pregnancy. Moreover, these results may provide insight into the role of the $A K R 1 C 1$ gene at the abovementioned phases of the estrous cycle and pregnancy. However, the functions of AKR1C1 in the ovary and uterus during the early estrous cycle and pregnancy in pigs are not known in detail. In the present study, we suggest that porcine AKR1C1 plays a pivotal role on oocyte ovulation and implantation in ovary and pregnancy maintenance of fetus in uterus.

On the other hand, $20 \alpha-H S D$ mRNA in goats was mainly localized in the endometrial epithelium on the caruncle side of the placenta on day 130 of pregnancy [13]. In mice, in situ hybridization analysis revealed that $20 \alpha-H S D$ mRNA was localized in the endometrial epithelial cells, maternal placental endothelial cells, and fetal epidermal cells during pregnancy [19]. These findings may be related to differences in the distribution of $20 \alpha-$ HSD between these species. Steroid metabolites of AKR1C enzymes rise at the onset of puberty [20,21]. FSH secretion stimulates the development of antral follicles, and FSH levels are greater in some lines of gilts with higher ovulation rates [22,23]. Considerable support for an association between $A K R 1 C$ genotypes and nipple number was detected, as well as some indication of an effect on age at puberty and possible ovulation rate [7]. Age at onset of puberty and ovulation rate at a specific age are negatively correlated traits in Meishan pigs because ovulation rate increases from puberty to later estrous cycles [24].

Pig AKR1C1 protein was most highly expressed in the ovary on day 0 of the estrous cycle, and was almost consistent with the mRNA expression pattern. This study shows that AKR1C1 protein and mRNA levels are expressed in a coordinated fashion in the ovary during the estrous cycle and pregnancy. However, this is not consistent with results in other animals, which show the presence of $20 \alpha$-HSD in the ovary and placenta $[9,11,12,25]$. In bovines, its expression increased according to the phase of the estrous cycle (unpublished data). However, the pattern in pigs is in 


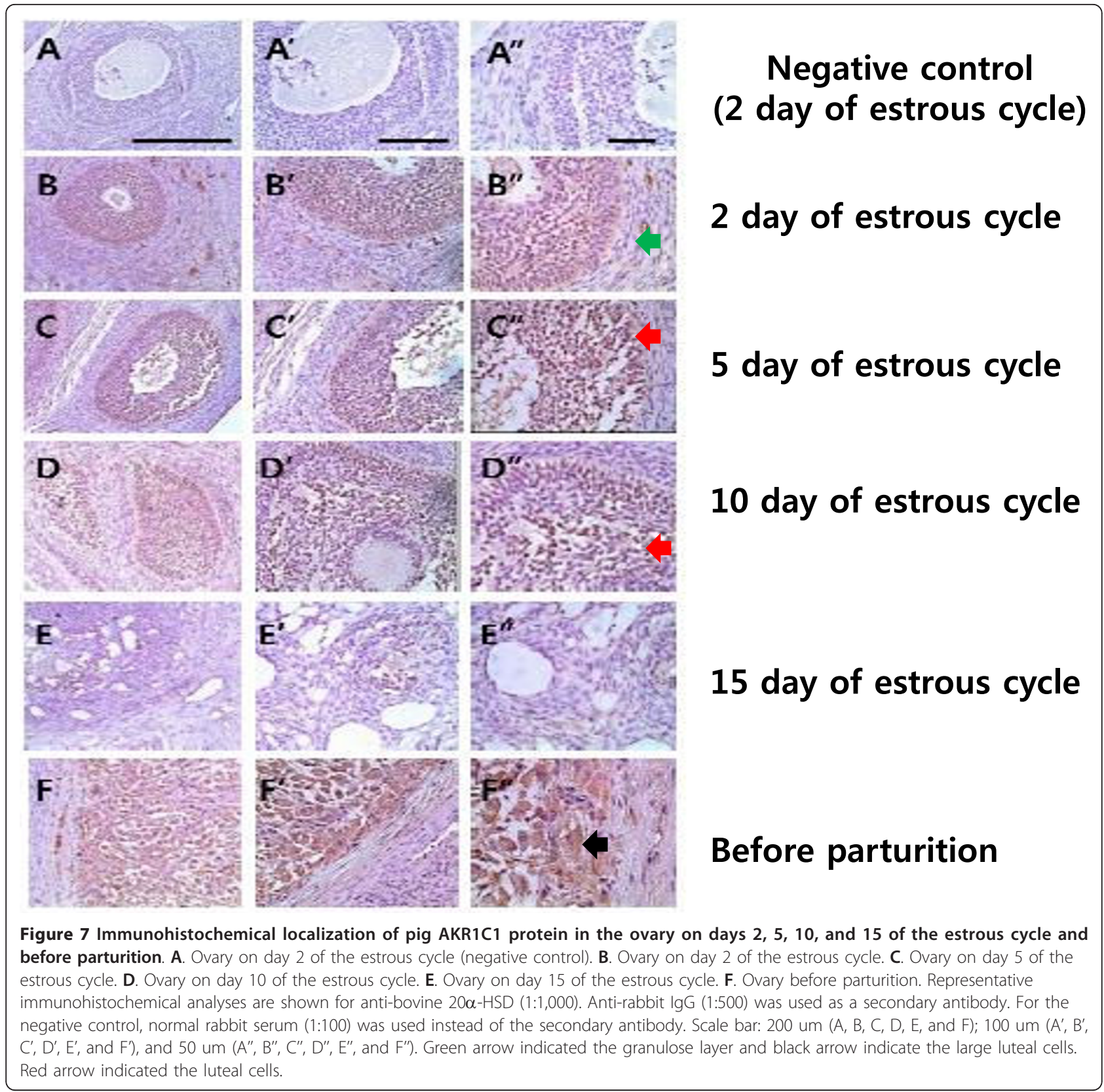

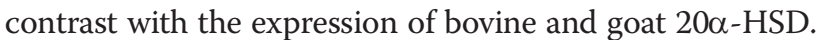
The isolated AKR1C1 cDNA was expressed in mammalian cells, and the protein product was detected by western blot at $37 \mathrm{kDa}$, identical to previous reports in other species: the baculovirus insect cell system in rat [25] and the E. coli system in goat, monkey, and rat $[9,19,26]$. Immunohistochemistry demonstrated that AKR1C1 is localized in large luteal cells. It was intensely expressed in luteal cells on day 5 of the early estrous cycle and before parturition. In cattle and deer, $20 \alpha-H S D$ was primarily expressed in large luteal cells of the corpus luteum during the late estrous cycle and pregnancy (unpublished data).
However, in pigs, the functions of AKR1C1 on ovulation have not been reported. This study represents the first report of specific expression levels and localization in the ovary and uterus during the estrous cycle and pregnancy period. Thus, further research is required to elucidate the function of AKR1C1 in the ovary and uterine endometrium during the estrous cycle and pregnancy.

\section{Conclusions}

We identified the nucleotide sequence and expression pattern of the porcine AKR1C1. Our study demonstrated that AKR1C1 mRNA and protein are coordinately 
expressed in the ovary throughout the estrous cycle. Porcine AKR1C1 mRNA and protein also were highly expressed in the uterus on day 30 of pregnancy. AKR1C1 was primarily localized in large luteal cells during the early stages of the estrous cycle and in the ovary before parturition. Thus, the porcine AKR1C1 gene might control important mechanisms during the estrous cycle. Further studies are needed to determine the functional significance of porcine AKR1C1 during estrous cycle and pregnancy.

\section{Acknowledgements}

The authors thank Dr. YC Chang (Catholic University) and Dr. HH Seong (Institute of Animal Science) for their helpful discussions and to Mrs YS Kang for her technical assistance.

\section{Author details}

${ }^{1}$ Animal Biotechnology, Graduate School of Bio \& Information Technology, Institute of Genetic Engineering, Hankyong National University, Ansung 456749, Korea. ${ }^{2}$ Department of Food and Nutrition, Hoseo University, Asan 336795, Korea. ${ }^{3}$ Division of Biological Science and Technology, Yonsei University, Wonju 220-710, Korea. ${ }^{4}$ Department of Animal Science, Chungbuk National University, Cheongju 361-763, Korea. ${ }^{5}$ Department of Veterinary Physiology, Veterinary Medical Science, The University of Tokyo, Tokyo 113-8657, Japan.

\section{Authors' contributions}

KSS, PN, SHK, SJY, JJP, and BWS performed the experiments. CWP, TN, and HS performed IHC. MHK drafted the manuscript. HHK, NHK, SYH, JTY, and KSM designed the study, supervised the experimental work, and revised the manuscript. All authors read and approved the final manuscript. These authors contributed equally to this paper.

\section{Competing interests}

The authors declare that they have no competing interests.

Received: 24 July 2011 Accepted: 20 October 2011

Published: 20 October 2011

\section{References}

1. Penning TM: Molecular endocrinology of hydroxysteroid dehydrogenase. Endocr Rev 1997, 18(3):281-305.

2. Jez JM, Bennett MJ, Schlegel BP, Lewis M, Penning TM: Comparative anatomy of the aldoketo reductase superfamily. Biochem J 1997, 326(Pt3):625-636.

3. Penning TM, Jin Y, Steckelbroeck S, Lanisnik Lizner T, Lewis M: Structurefunction of human 3 alpha-hydroxysteroid dehydrogenases: genes and proteins. Mol Cell Endocrinol 2004, 215(1-2):63-72.

4. Zhang Y, Dufort I, Rheault P, Luu-The V: Characterization of a human 20aHSD. J Mol Endocrinol 2000, 25(2):221-228.

5. Stanbrough M, Bubley GJ, Ross K, Golub TR, Rubin MA, Penning TM, Febbo PG, Balk SP: Increased expression of genes converting adrenal androgens to testosterone in androgen-independent prostate cancer. Cancer Res 2006, 66(5):2815-2825.

6. Qin K, Ehrmann DA, Cox N, Refetoff S, Rosenfield RL: Identification of a functional polymorphism of the human type 5 17beta-hydroxysteroid dehydrogenase gene associated with polycystic ovary syndrome. J Clin Endocrinol Metab 2006, 91(1):270-276.

7. Nonneman DJ, Wise TH, Ford JJ, Kuehn LA, Rohrer GA: Characterization of the aldo-keto reductase $1 \mathrm{C} 1$ gene cluster on pig chromosome 10 : possible associations with reproductive traits. BMC Vet Res 2006, 13:28

8. Naumann JM, Messinger J, Bureik M: Human 20a-hydroxysteroid dehydrogenase (AKR1C1)-dependent biotransformation with recombinant yeast Schizosaccharomyces pombe. J Biotechnol 2010, 150(1):161-170.

9. Jayasekara WS, Yonezawa T, Ishida M, Yamanouchi K, Nishihara M: Molecular cloning of goat 20a-hydroxysteroid dehydrogenase cDNA. J Reprod Dev 2004, 50(3):323-331.
10. Shiota K, Seong HH, Noda K, Hattori N, Ikeda A, Ogura A, Itagaki S, Takahashi M, Ogawa T: 20a-Hydroxysteroid dehydrogenase activity in rat placenta. Endocrine J 1993, 40(6):673-681.

11. Seong HH, Shiota K, Noda K, Ogura A, Asona T, Takahashi M: Expression of activities of two 20a-hydroxysteroid dehydrogenase isozymes in rat corpora lutea. J Reprod Fert 1992, 96(2):573-580.

12. Seong HH, Min KS, Kang MH, Yoon JT, Jin HJ, Chung HJ, Chang WK, Yun SG, Shiota K: Change in ovarian and placental 20a-HSD activity during the pregnancy in the rat. Asian J Anim Sci 2002, 16(2):342-347.

13. Jayasekara WS, Yonezawa T, Ishida M, Yamanouchi K, Nishihara M: Expression and possible role of 20a-hydroxysteroid dehydrogenase in the placenta of the goat. J Reprod Dev 2005, 51(2):265-272.

14. Bradford MM: A rapid and sensitive method for the quantitation of microgram quantities of protein utilizing the principle of protein-dye binding. Anal Biochem 1976, 72:248-254.

15. Min KS, Hiyama T, Seong HH, Hattori N, Tanaka S, Shiota K: Biological activities of tethered equine chorionic gonadotropin $(\mathrm{eCG})$ and its deglycosylated mutants. J Reprod Dev 2004, 50(3):297-304.

16. Rodriguez C, Tomas A, Alves E, Ramirez O, Arque M, Munoz G, Barragan C, Varona L, Silio L, Amills M, Norguera JL: QTL mapping for teat number in an Iberian-by-Meishan pig intercross. Anim Genet 2005, 36(6):490-496.

17. Rohrer GA, Ford JJ, Wise TH, Vallet JL, Christenson RK: Identification of quantitative trait loci affecting female reproductive traits in a multigeneration Meishan-White composite swine population. J Anim Sci 1999, 77(6):1385-1391.

18. Albarracin $C T$, Parmer TG, Duan WR, Nelson SE, Gibori G: Identification of a major prolactin-regulated protein as 20a-hydroxysteroid dehydrogenase: coordinate regulation of its activity, protein content, and messenger ribonycleic acid expression. Endocrinology 1994, 134(6):2453-2460.

19. Ishida M, Chang K, Hirabayashi K, Nishihara M, Takahashi M: Cloning of mouse 20a-hydroxysteroid dehydrogenase CDNA and its mRNA localization during pregnancy. J Reprod Dev 1999, 45(5):321-329.

20. Rittner HL, Lee PD, Blum WF, Doerr HG, Steiss J, Kreuder J, Rascher W, Kiess W: Developmental pattern of serum 3 alpha-androstandediol glucuronide. J Endocrinol Invest 1997, 20(3):138-143.

21. Riddck LM, Garibaldi LR, Wang ME, Senne AR, Klimah PE, Clark AT, Levine LS, Oberfield SE, Pang ST: 3 alpha-androgeanediol glucuronide in premature and normal pubarche. J Clin Endocrinol Metab 1991, 72(1):46-50.

22. Ford JJ, Zimmerman DR, Wise TH, Leymaster KA, Christenson RK: Increased plasma follicle-stimulating hormone concentrations in prebubertal gilts from lines selected for increased number of corpora lutea. J Anim Sci 2001, 79(7):1877-1882.

23. Knox RV, Vatzias $\mathrm{G}$, Naber $\mathrm{CH}$, Zimmerman DR: Plasma gonadotropins and ovarian hormones during the estrous cycle in high compared to low ovulation rate gilts. J Anim Sci 2003, 81(1):249-260.

24. Christenson RK: Ovulation rate and embryonic survival in Chinese Meishan and white corssbred pigs. J Anim Sci 1993, 71(11):3060-3066.

25. Mao J, Duan RW, Zhong L, Gibori G, Azhar S: Expression, purification and characterization of the rat luteal 20a-hydroxysteroid dehydrogenase. Endocrinology 1997, 138(1):182-190.

26. Higaki Y, Kamiya T, Usami N, Shintani S, Shiraishi H, Ishikura S, Yamanoto I, Hara A: Molecular characterization of two monkey dihydrodiol dehydrogenases. Drug Metab Pharmacokinet 2002, 17(4):348-356.

doi:10.1186/1477-7827-9-139

Cite this article as: Seo et al:: Expression of aldo-keto reductase family 1 member C1 (AKR1C1) gene in porcine ovary and uterine endometrium during the estrous cycle and pregnancy. Reproductive Biology and Endocrinology 2011 9:139. 